\title{
Haemoglobin analysis on whole blood by reflectance photometry
}

\author{
John A. Lott and Elias Khabbaza \\ Department of Pathology, The Ohio State University Medical Center, Doan Hall \\ $N-329$, Columbus, Ohio 43210, USA
}

\section{Introduction}

New automated analytical methods in the clinical laboratory continue to appear, attesting to the development and maturation of the field. The progression has been from continuous flow analysers, to discrete analysers, and currently to 'reagentless' analysers (i.e. those using dry reagent-impregnated strips or pads) [1 and 2]. Stability under dry conditions, insensitivity to storage temperature fluctuations and a small, compact size are advantages of the dry reagent-impregnated strips or pads.

The purpose of this study was to evaluate the Seralyzer (Ames Division of Miles Laboratories, Elkhart, Indiana, USA) reflectance photometer and reagent strip system for the analysis of haemoglobin in whole blood. Three laboratories collaborated in this study, and each used the Coulter-S (Coulter Electronics, Inc., Hialeah, Florida, USA). The study was designed to test the comparability of the Seralyzer and Coulter-S haemoglobin methods on fresh patient specimens. Goals of the study included determining if there was between-method bias, estimating between-day precision, and testing for possible interferences from lipaemia, bilirubin, and carboxyhaemoglobin. Other objectives were to identify any critical steps in the procedure, limitations, and the applicability of the method for haemoglobin analysis in clinical laboratories.

\section{Materials and methods}

\section{Test strips}

The test strips consist of an absorbent reagent pad attached to a firm plastic support. The inert pads are impregnated with reagent, and each $100 \mathrm{~g}$ of impregnating reagent contains $50 \mathrm{~g}$ potassium ferricyanide, $19 \mathrm{~g}$ potassium dihydrogen phosphate, $19 \mathrm{~g}$ potassium monohydrogen phosphate and $12 \mathrm{~g}$ saponin.

The reaction used is:

Haemoglobin $\stackrel{\text { ferricyanide }}{\longrightarrow}$ methemoglobin.

Two lots of test strips were used at each of the three evaluation sites. Calibration was performed with solutions of D \& C Red No. 33 dye (Ames) at $400 \mathrm{mg} / \mathrm{l}$ and $900 \mathrm{mg} / \mathrm{l}$ as described in the Seralyzer instrument manual [3]. The instrument was set at 7.2 and and $16.6 \mathrm{~g} / \mathrm{dl}$ haemoglobin, respectively, with the dye solutions. The Coulter-S counters were calibrated for haemoglobin analysis using the well-known hemiglobincyanide spectrophotometric procedure recommended by the National Committee for Clinical Laboratory Standards (NCCLS) [4].

\section{Instrument}

The reflectance of the strips was measured at $535 \mathrm{~nm}$ in the Seralyzer. The percentage reflectance of the pads was converted to concentration of haemoglobin with the simplified Kubelka-Munk [5] equation by the microprocessor in the instrument: $K / S=(1-R)^{2} / 2 R$, where $K$ is the molar absorptivity, $S$ is the scattering coefficient, and $R$ is the reflectance. $K / S$ is proportional to concentration. The optics and method of data reduction have been described in more detail elsewhere [1].

\section{Method}

Well-mixed whole blood anticoagulated with $0.07 \mathrm{ml} 150$ $\mathrm{g} / 1 \mathrm{~K}_{3}$ EDTA per $7.0 \mathrm{ml}$ blood was used for analysis. Utilizing capillary action, a $10 \mu \mathrm{l}$ glass capillary micropipette was filled with either whole blood or a control. After the outside of the capillary was wiped dry, the filled capillary was dropped into a $5 \mathrm{ml}$ test-tube containing $800 \mu \mathrm{l}$ of distilled water providing an 81-fold dilution of the whole blood. The tube was stoppered and mixed by agitation along the length of the capillary until a uniformly coloured solution was obtained.

After placing a strip on the strip carriage, $30 \mu \mathrm{l}$ of the specimen was pipetted onto the centre of the pad. The start button was pushed, and the strip carriage was inserted into the Seralyzer. After approximately $60 \mathrm{~s}$, the results were available on the digital display.

\section{Comparison studies}

Fresh whole blood specimens from patients were reanalysed in duplicate on the Coulter-S and Seralyzer at all three locations. At the third site, the specimens were also analysed in duplicate on an IL 282 CO-Oximeter (Instrumentation Laboratories, Lexington, Massachusetts, USA).

\section{Quality control}

Streck Hematology Controls I, II and III (Streck Laboratories, Omaha, Nebraska, USA) were used at all three sites. The approximate haemoglobin concentrations of the controls were $8 \mathrm{~g} / \mathrm{dl}, 15 \mathrm{~g} / \mathrm{dl}$, and $22 \mathrm{~g} / \mathrm{dl}$, and the same lots of controls were used at all three sites. The controls were analysed in triplicate on each of the 20 days of the study at all three sites. The Streck controls' haemoglobin concentrations had been established with the NCCLS method [4]. 
J. A. Lott and E. Khabbaza Haemoglobin analysis by reflectance photometry

Table 1. Seralyzer versus Coulter-S: comparative data using fresh whole blood specimens.

Site A

\begin{tabular}{ccccc}
\hline $\begin{array}{c}\text { Haemoglobin } \\
(\mathrm{g} / \mathrm{dl})\end{array}$ & $N$ & $\begin{array}{c}\text { Seralyzer } \\
\text { mean }\end{array}$ & $\begin{array}{c}\text { Coulter-S } \\
\text { mean }\end{array}$ & $\begin{array}{c}\text { Mean } \\
\text { difference }\end{array}$ \\
\hline$<8 \cdot 1$ & 16 & $7 \cdot 11$ & $6 \cdot 97$ & $+0 \cdot 14$ \\
$8 \cdot 1-12$ & 20 & $10 \cdot 69$ & $10 \cdot 70$ & $-0 \cdot 01$ \\
$12 \cdot 1-14$ & 12 & $13 \cdot 34$ & $13 \cdot 25$ & $+0 \cdot 09$ \\
$14 \cdot 1-16$ & 9 & $15 \cdot 02$ & $15 \cdot 00$ & $+0 \cdot 02$ \\
$16 \cdot 1-18$ & 17 & $17 \cdot 38$ & $16 \cdot 94$ & $+0 \cdot 44$ \\
$18 \cdot 1-20$ & 3 & $20 \cdot 25$ & $19 \cdot 38$ & $+0 \cdot 87$ \\
Above 20 & 19 & $22 \cdot 63$ & $22 \cdot 06$ & $+0 \cdot 57$
\end{tabular}

\section{Site B}

$\begin{array}{rrrrr}<8 \cdot 1 & 9 & 7 \cdot 56 & 7 \cdot 32 & +0 \cdot 23 \\ 8 \cdot 1-12 & 31 & 10 \cdot 52 & 10 \cdot 46 & +0 \cdot 06 \\ 12 \cdot 1-14 & 25 & 13 \cdot 09 & 12 \cdot 94 & +0 \cdot 15 \\ 14 \cdot 1-16 & 16 & 15 \cdot 04 & 14 \cdot 91 & +0 \cdot 13 \\ 16 \cdot 1-18 & 12 & 17 \cdot 09 & 16 \cdot 94 & +0 \cdot 15 \\ 18 \cdot 1-20 & 4 & 18 \cdot 19 & 18 \cdot 34 & -0 \cdot 15\end{array}$

Site C

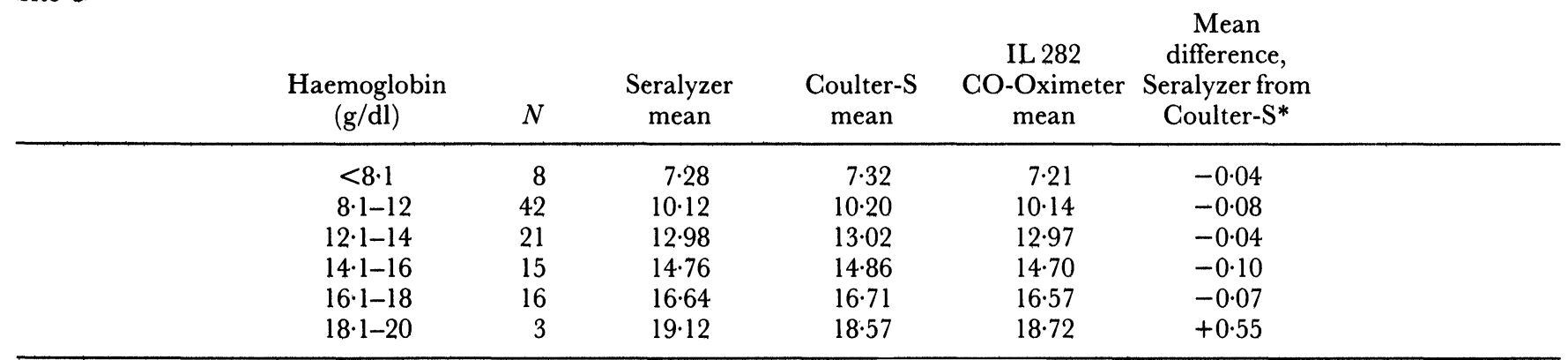

* Mean of Seralyzer results (column 3) minus mean of Coulter-S results (column 4).

Table 2. Correlation statistics on patient fresh blood analyses.

\begin{tabular}{ccccccc}
\hline & Seralyzer $(\mathrm{Y})$ & \multicolumn{2}{c}{ Coulter-S $(\mathrm{X})$} & \multicolumn{2}{c}{ Standard } \\
Site & $N$ & Slope & $N$ & Intercept & error & R \\
\hline A & 96 & $1 \cdot 04$ & 96 & $-0 \cdot 31$ & $0 \cdot 54$ & 0.99 \\
B & 97 & 0.99 & 97 & $0 \cdot 21$ & $0 \cdot 39$ & 0.99 \\
C & 105 & $1 \cdot 01$ & 105 & $-0 \cdot 14$ & $0 \cdot 44$ & 0.99 \\
C & 105 & 1.00 & $105 *$ & $0 \cdot 01$ & 0.53 & 0.98 \\
\hline
\end{tabular}

\footnotetext{
* CO-Oximeter results.
}

\section{Interference studies}

Lipaemic specimens, or those with total bilirubin concentrations between 4 and $32 \mathrm{mg} / \mathrm{dl}$, were investigated for possible interferences with both the seralyzer and Coulter-S methods. For the lipaemic and icteric specimens, the cells were washed twice with a solution containing $154 \mathrm{mmol} / 1$ sodium chloride and $1.5 \mathrm{~g} / \mathrm{l}$ $\mathrm{K}_{3}$ EDTA, and the volume was restored to the original volume with the same solution. The erythrocyte count of the specimens was used to determine whether any cells had been lost during washing. For almost all of the specimens, the count before and after washing agreed within 1 to $2 \%$. Where these values differed by more than
$1 \%$, the haemoglobin concentration determined after the cell wash was multiplied by the factor: before wash count divided by after wash count. This was done to correct for minor cell loss in washing and to permit the accurate determination of the bilirubin and lipaemia interferences.

The possibility of interference from carbon monoxide was also investigated. Since interference by carboxyhaemoglobin in total haemoglobin assays occurs owing to the slow conversion of carboxyhaemoglobin to methemoglobin [6], the rate of conversion was investigated. After diluting $20 \mu \mathrm{l}$ whole blood with $1.6 \mathrm{ml}$ of distilled water, the sample was divided in half, and carbon monoxide was 


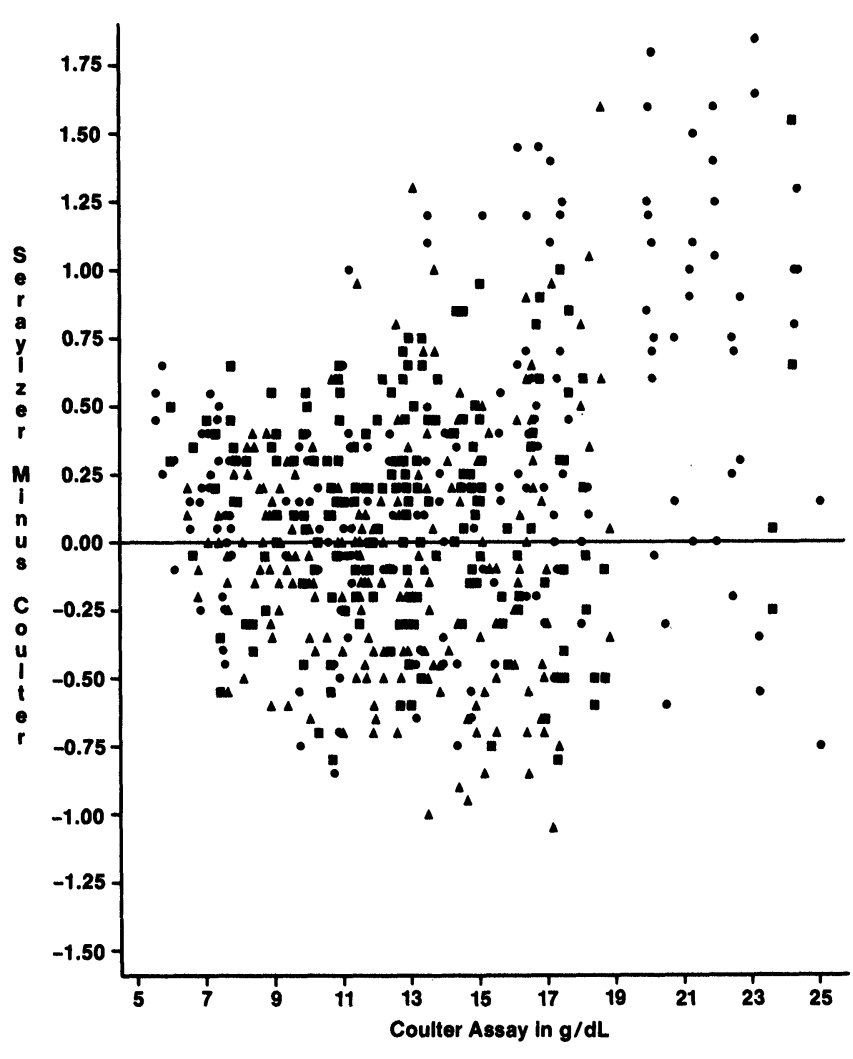

Figure 1. Data on 298 patients analysed for haemoglobin by the Seralyzer and Coulter-S for site $A(\mathbf{O})$, site $B(\mathbf{\square})$, and site $C$ $(\Delta)$.

bubbled through one aliquot for $5 \mathrm{~min}$. The two samples were analysed for haemoglobin on the Seralyzer, and the reflectance of the strip at $535 \mathrm{~nm}$ was followed over time.

\section{Results and discussion}

\section{Instrument}

The Seralyzer is easy to use and simple to calibrate. The approximate 1 min test time makes it suitable for smaller laboratories where only haemoglobin is measured.

\section{Method}

The method was easy to perform; however, pipetting of the haemolysed and diluted blood onto the strips is a critical step. To obtain reproducible results, the specimen must be pipetted onto the middle of the strip. The reagent pad on the strip must not be touched by the pipette, as this may wash out the reagents or produce a pimple on the pad, both of which spoil the test. The strip must be inserted within $5 \mathrm{~s}$ of pushing the start button. Some training and practice is necessary for any new user when operating the instrument. Replicate results done at the same time should not differ by more than about $0.3 \mathrm{~g} / \mathrm{dl}$. A person with some familiarity with basic laboratory techniques should be able to perform the tests after reading the instruction manual [3], being shown how to perform the test, and then practicing the calibration and analysis technique for approximately $1 \mathrm{~h}$.

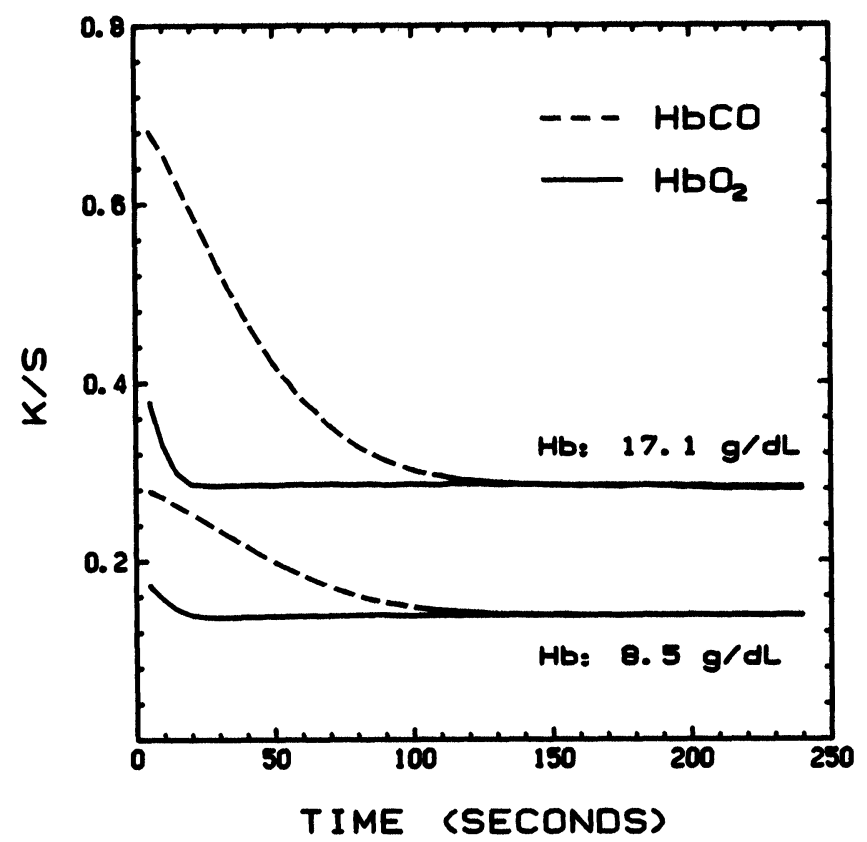

Figure 2. Time profile of conversions of oxyhaemoglobin (solid line) or carboxyhaemoglobin (dashed line) to methemoglobin as determined by reflectance photometry and the $K / S$ equation. The $K / S$ value is proportional to concentration. Upper curve, haemoglobin of $17.1 \mathrm{~g} / \mathrm{dl}$; lower curve, haemoglobin of $8.5 \mathrm{~g} / \mathrm{dl}$.

Table 3. Seralyzer haemoglobin precision: combined data from all three sites.

\begin{tabular}{lccc}
\hline Control number & I & II & III \\
Number of days & 20 & 20 & 20 \\
Number of analyses & 183 & 183 & 117 \\
Mean & $8 \cdot 2$ & 14.5 & $21 \cdot 1$ \\
Within-run data & & & \\
SD & 0.18 & 0.31 & 0.52 \\
CV (\%) & $2 \cdot 2$ & $2 \cdot 1$ & 2.5 \\
Between-run data & & & \\
SD & 0.16 & 0.28 & 0.45 \\
CV (\%) & $2 \cdot 0$ & 1.9 & $2 \cdot 1$ \\
\hline
\end{tabular}

\section{Comparative data on patient specimens}

Comparative data obtained on fresh whole blood specimens at the three sites are shown in table 1 , and the correlation statistics are detailed in table 2 . The reference instruments (Coulter-S) were calibrated with different sources of haemoglobin at the three sites. Given the excellent agreement between the Seralyzer and the Coulter instruments at all sites, it is reasonable to conclude that the Seralyzer gives results that are a good estimate of the true haemoglobin concentrations. Using an IL CO-Oximeter at site $\mathrm{C}$, precise results were confirmed since agreement with the Seralyzer was very good. Figure 1 shows the differences between the Seralyzer and Coulter-S haemoglobin determinations on 298 fresh patient specimens at the three sites. Below 19 $\mathrm{g} / \mathrm{dl}$ hemoglobin no statistically significant bias existed between the Seralyzer or the Coulter-S.

The Seralyzer cannot be used for specimens with less than $5 \mathrm{~g} / \mathrm{dl}$ haemoglobin. Above $19 \mathrm{~g} / \mathrm{dl}$ hemoglobin, the 
Table 4. Haemoglobin interference studies.

\begin{tabular}{|c|c|c|c|c|}
\hline & \multicolumn{2}{|c|}{ Coulter-S } & \multicolumn{2}{|c|}{ Seralyzer } \\
\hline & $\begin{array}{l}\text { Before wash } \\
\quad(\mathrm{g} / \mathrm{dl})\end{array}$ & $\begin{array}{l}\text { After wash } \\
(\mathrm{g} / \mathrm{dl})\end{array}$ & $\begin{array}{l}\text { Before wash } \\
(\mathrm{g} / \mathrm{dl})\end{array}$ & $\begin{array}{l}\text { After wash* } \\
(\mathrm{g} / \mathrm{dl})\end{array}$ \\
\hline \multicolumn{5}{|c|}{$\begin{array}{l}\text { Specimens } \\
\text { Icteric }(N=22)\end{array}$} \\
\hline Mean & $11 \cdot 44$ & $11 \cdot 35$ & $11 \cdot 70$ & $11 \cdot 66$ \\
\hline SD & $1 \cdot 85$ & 1.87 & 1.86 & 1.95 \\
\hline \multicolumn{5}{|c|}{ Lipemic $(N=9)$} \\
\hline Mean & $12 \cdot 36$ & $12 \cdot 16$ & $12 \cdot 23$ & $12 \cdot 23$ \\
\hline SD & $3 \cdot 34$ & $3 \cdot 27$ & $3 \cdot 35$ & $3 \cdot 24$ \\
\hline
\end{tabular}

Note: The sodium chloride-EDTA solution contained 154 $\mathrm{mmol} / \mathrm{L}$ sodium chloride and $1.5 \mathrm{~g} / \mathrm{l} \mathrm{K}_{3}$ EDTA. See text for details.

* Corrected for cell loss during washing

Seralyzer showed a significant positive bias at sites A and C (table 1). Specimens with a haemoglobin above $19 \mathrm{~g} / \mathrm{dl}$ should be diluted with $154 \mathrm{mmol} / \mathrm{l}$ sodium chloride prior to analysis on the Seralyzer.

\section{Precision}

No statistically significant between-lot variation of the strips was observed for the Seralyzer results on the Streck controls I, II and III, so the data from the three sites were merged. Also there was no bias by the t-test between the three sites for the control results (table 3). Controls I and II were analysed in triplicate on each of 20 days, and control III was analysed on each of about 10 days at each site. The within-run standard deviation (SD) was calculated each day; the within-run SDs in table 3 are the averages of the within-run SDs.

The within-day means were calculated for each control, and these data were used to calculate the between-run SDs. The use of the means is probably the reason why the between-day SDs are slightly smaller than the within-run SDs. The between-run average coefficient of variation $(\mathrm{CV})$ of about $2 \%$ is well within the medically acceptable limits of $3 \%$ at 8 to $21 \mathrm{~g} / \mathrm{dl}$ haemoglobin [7].

\section{Interference study}

The effects of bilirubin and lipaemia are summarized in table 4 . The effect of bilirubin is very slight with both instruments. Specimens with $30 \mathrm{mg} / \mathrm{dl}, 31 \mathrm{mg} / \mathrm{dl}$, and 32 $\mathrm{mg} / \mathrm{dl}$ bilirubin showed at most a haemoglobin which was $0.3 \mathrm{~g} / \mathrm{dl}$ higher with the Coulter-S before washing. The Seralyzer method was unaffected by bilirubin. The effect of lipaemia is negligible, and the difference seen before and after washing the cells was due to experimental error.

Carbon monoxide does not interfere in the determination of haemoglobin; however, carboxyhaemoglobin is converted to methemoglobin more slowly than oxyhaemoglobin (figure 2). The seralyzer does not display a result until a stable reflectance is obtained. In the presence of large amounts of carboxyhaemoglobin, in may take 2 to 3 min before a result is obtained.

\section{Conclusions}

Using dry reagent strips, the Seralyzer provides medically acceptable results for whole blood haemoglobin. The usable analytical range of the instrument is 5 to $19 \mathrm{~g} / \mathrm{dl}$. Neither bilirubin, carbon monoxide, nor lipaemia interfere.

\section{Acknowledgements}

The authors wish to thank Dan Wong of Ames for the carboxyhaemoglobin interference study and Larry W. Clark for technical assistance and for reviewing the manuscript. Budd Mott (Cushing Municipal Hospital, Cushing, Oklahoma, 74023, USA) provided the data from site B, and Dr Michael Shehan (Good Samaritan Hospital, Portland, Oregon, 97210, USA) provided the data from site $\mathrm{C}$.

\section{References}

1. Karmen, A. and Lent, R., The Journal of Clinical Laboratory Automation, 2 (1982), 284

2. Bandi, Z. L., Fuller, J. B., Bee, D. E. and James, G. P., Clinical Chemistry, 27 (1981), 27.

3. Instruction Manual, Ames Seralyzer (Ames Company, Division of Miles Laboratories, Elkhart, Indiana, USA).

4. National Committee for Clinical Laboratory Standards, Standard H7-T: Hemiglobincyanide Spectrophotometric Procedure for Hemoglobinometry Standardization (NCCLS, Villanova, Pennsylvania, 1979).

5. Kortuem, G., Reflectance Spectroscopy (New York, Springer Verlag, 1969), p. 106.

6. TAylor, J. D. and Miller, J. D. M., American Journal of Clinical Pathology, 43 (1965), 265.

7. Barnett, R. N., American Journal of Clinical Pathology, 50 (1968), 671. 


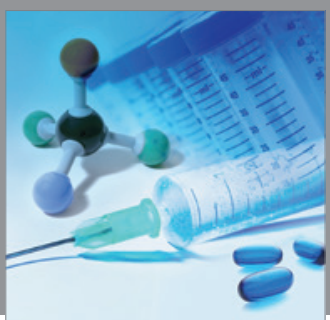

International Journal of

Medicinal Chemistry

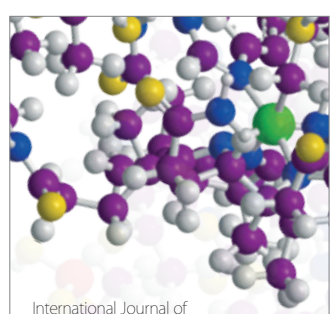

Carbohydrate Chemistry

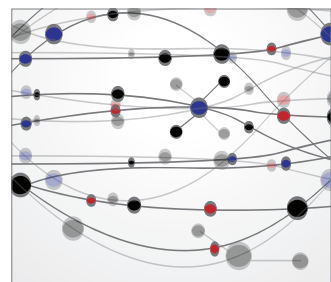

The Scientific World Journal
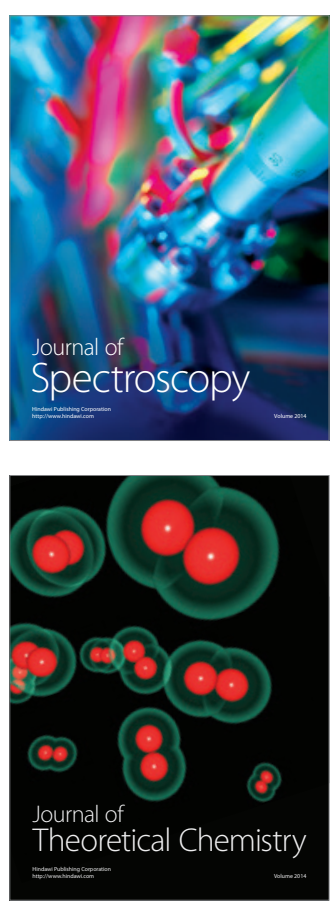
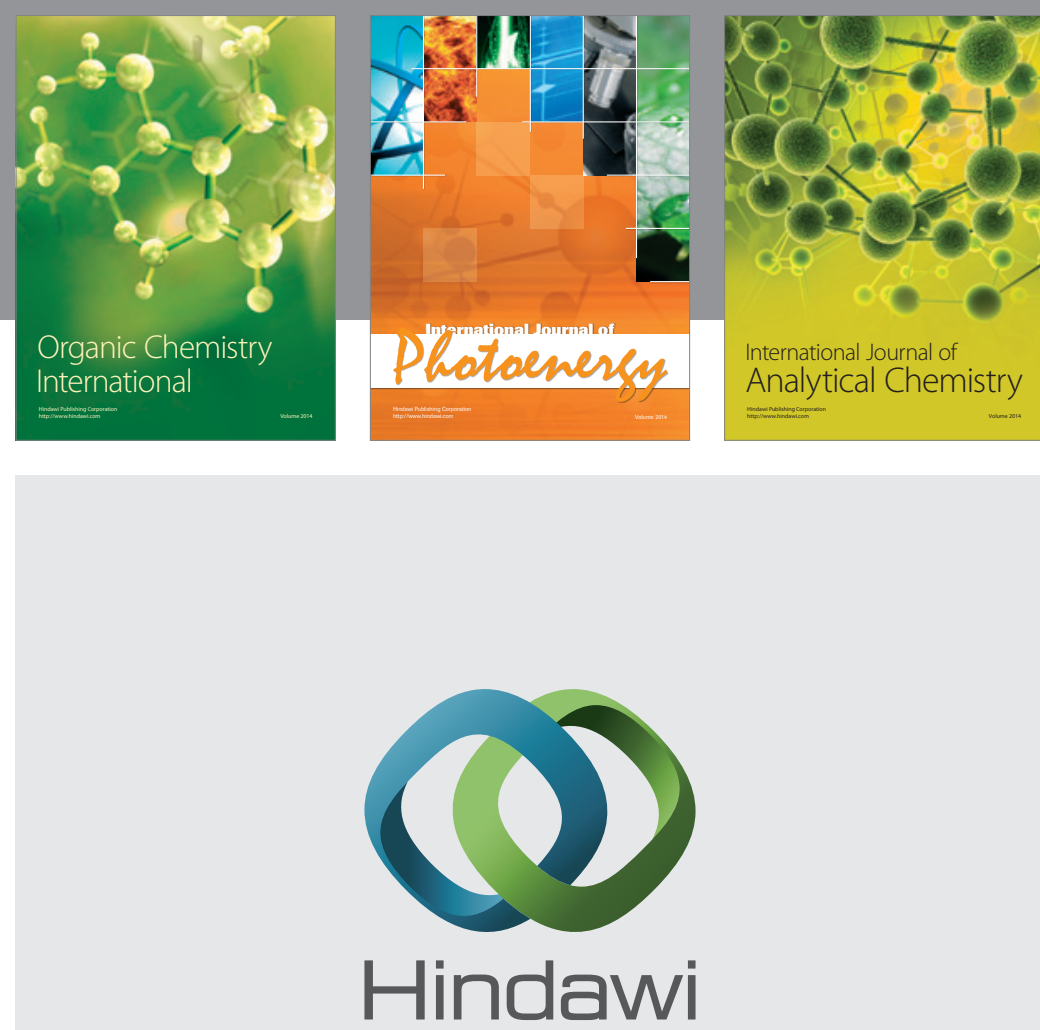

Submit your manuscripts at

http://www.hindawi.com
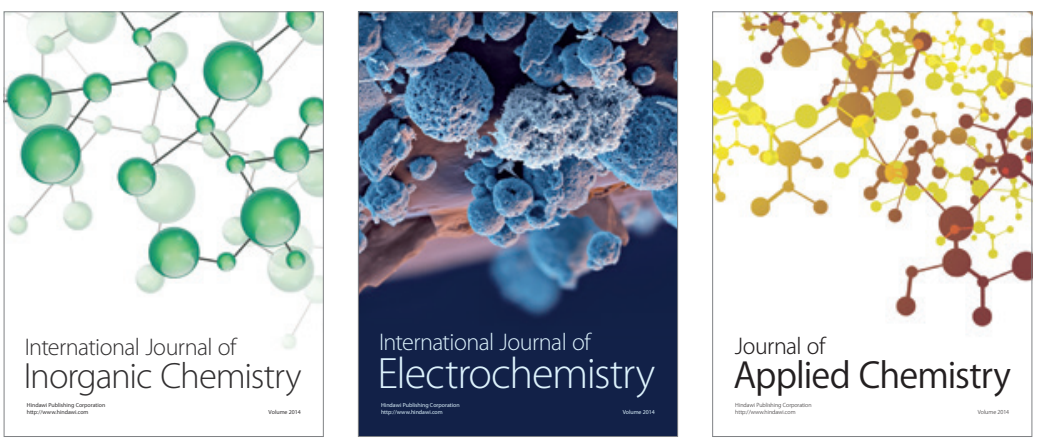

Journal of

Applied Chemistry
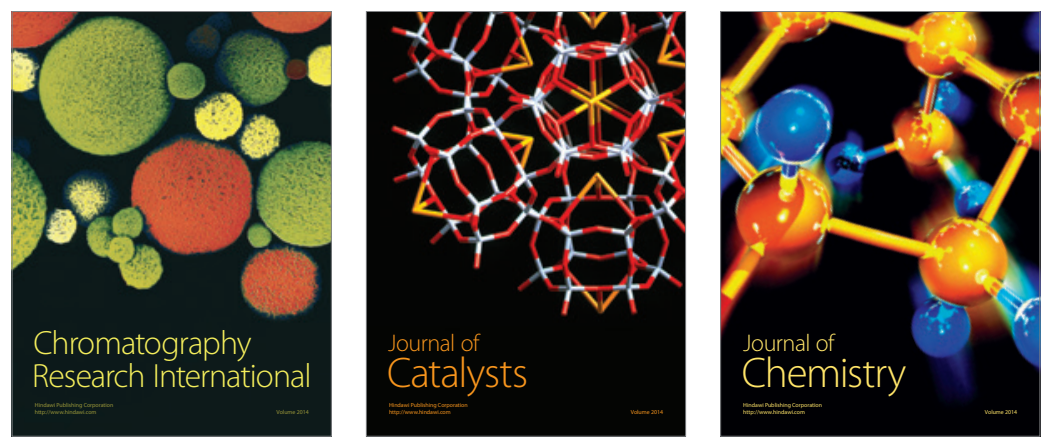
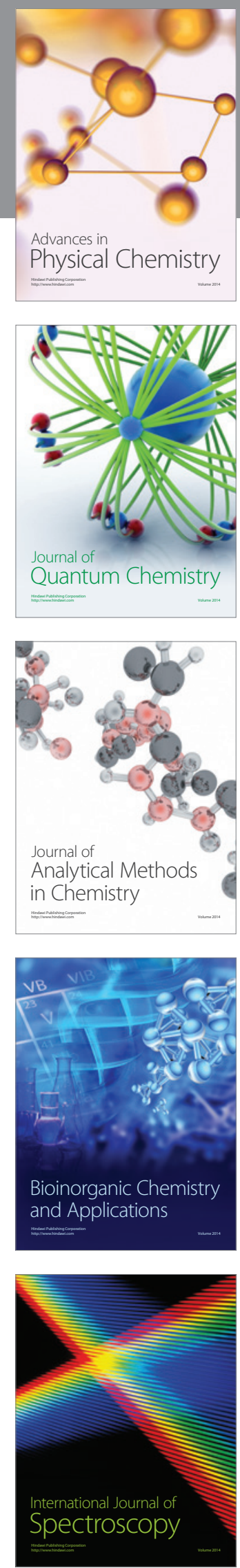